\title{
KINETICS OF OXIDATION OF HEXAKIS ( $p$-CHLOROANILINE) COBALT (II) CHLORIDE BY POTASSIUM IODATE
}

* B. Edison, ** S. Peter

\begin{abstract}
$V_{\text {it }} B_{12}$ is an important complex of cobalt ${ }^{3}$. The rate of oxidation of the Synthesized complex Hexakis ( $\mathrm{p}$-chloral aniline) cobalt (II) chloride follows first order kinetics with respect to the complex and oxidant potassium lodate ${ }^{1,2,4.8}$ in aqueous medium. Increasing in the concentration of complex solution increases the rate of the oxidation. increase in the concentration of the oxidant also increases the rate of the oxidation. The rate of the reaction is studied by changing the acid concentrations of the medium, by changing the temperature and by introducing the neutral salt $(\mathrm{NaCl})$ in the Medium. From this study the kinetic parameters Ea, $A, \Delta S^{*}, \Delta G^{*}, \Delta H^{*}$ are found out. From the observed facts it is infered that the reaction follows three steps.
\end{abstract}

\section{Preparation of the complex}

P-chloro aniline is a unidendate ligand. The metal chloride (cobalt chloride) and ligand are taken in the molar ratio 1:6. The cobaltous chloride and p-chloro aniline dissolved in methanol and purified by washing with benzene and sprit.

* Postgraduate and Research Department of Chemistry, St. Joseph's College (Autonomous) Trichy - 620002

** Reader, Postgraduate and Research Department of Chemistry, St. Joseph's College (Autonomous) Trichy - 620002 
The inorganic compounds potassium iodate, sodium chloride, Hydrochloric acid were analytically pure.

\section{Analysis of the complex}

The metal percentage is found out by complexometric ${ }^{9}$ analysis using cobalt murroxide indicator with EDTA. It is found that the complex is an octahedral one with 6 ligands. coordinated to the metal; the same result is confirmed by conductance study.

From the conductance study it is known that the complex is a $1: 2$ electrolyte and 2 chloride ions are present outside the complex sphere.

\section{Kinetic study}

An electrically operated thermostat with a jumbo contact thermometer working inconjugation with an electronic relay, which maintained temperature accurately with fluctuation not more than $0.02^{\circ} \mathrm{C}$ was used. The bath liquid was water and it was covered with a layer of thermocouple bits to minimize heat and water loss due to radiation.

In a typical experiment the required volume of potassium iodate, complex in water and the mixture were pipetted out and transferred into a double walled beaker provided with an inlet and outlet for circulating water from the thermostat at the desired temperature. The reaction was started by pipetting out the required quantity of oxidant and transfered it into the mixture in the double wall beaker. The total volume of the reaction mixture was always $50 \mathrm{ml}$, and the stopwatch was started. The platinum electrode and standard Calomel electrode was dipped in the double wall beaker. The emf of the cell was measured, periodically using Equip-Tronic Digital potentiometric while the reaction mixture was continuously stirred using a magnetic stirrer.

\section{Results and discussion}

The kinetic study of this reaction is studied using potentiometric (Equip-tronic digital). The rate of the reaction is found to be directly proportional with concentration of the complex, concentration of the oxidant, acidity of the medium and concentration of neutral salt present in the medium. From this it is concluded that the reaction follows First order kinetics with respect to complex and oxidant. The kinetics is studied at various temperatures, the rate of the reaction is found to increase with increase in temperature. The table is given below, 


\begin{tabular}{|c|c|c|c|c|c|c|c|}
\hline \multirow{2}{*}{ No } & Time & \multicolumn{3}{|c|}{ EMF (Nolts) } & \multicolumn{3}{c|}{$4+$ Log (Et-Eá) } \\
\cline { 3 - 8 } & (Min) & $312 \mathrm{~K}$ & $317 \mathrm{~K}$ & $322 \mathrm{~K}$ & $312 \mathrm{~K}$ & $317 \mathrm{~K}$ & $322 \mathrm{~K}$ \\
\hline 1 & 0 & 0.196 & 0.260 & 0.348 & 2.9053 & 3.3100 & 3.3844 \\
2 & 5 & 0.180 & 0.210 & 0.336 & 2.8123 & 3.2186 & 3.2734 \\
3 & 10 & 0.168 & 0.172 & 0.301 & 2.7404 & 3.1690 & 3.0042 \\
4 & 15 & 0.164 & 0.145 & 0.260 & 2.7139 & 3.1220 & 2.8989 \\
5 & 20 & 0.162 & 0.133 & 0.242 & 2.6800 & 2.9737 & 2.7734 \\
6 & 25 & 0.160 & 0.122 & 0.223 & 2.6542 & 2.8630 & 2.6923 \\
7 & 30 & 0.157 & 0.109 & 0.203 & 2.6280 & 2.7762 & 2.5560 \\
8 & 35 & 0.154 & 0.096 & 0.195 & 2.5471 & 2.6430 & 2.4913 \\
9 & 40 & 0.152 & 0.082 & 0.179 & 2.4790 & 2.6180 & 2.2552 \\
10 & á & 0.054 & 0.052 & 0.144 & - & - & - \\
\hline
\end{tabular}

Oxidation of the complex

The ligand in the complex undergoes oxidation as shown below $1 \mathrm{O}_{3}^{-}+\mathrm{H}^{+} \leftrightarrows \mathrm{HIO}_{3}$ $\mathrm{Cl}-\mathrm{C}_{6} \mathrm{H}_{5}-\mathrm{NH}_{2}+\mathrm{H}^{+} \quad \leftrightarrows \quad \mathrm{Cl}-\mathrm{C}_{6} \mathrm{H}_{5}-\mathrm{N}^{+} \mathrm{H}_{3}$

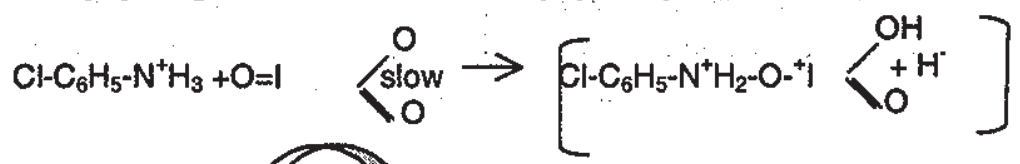

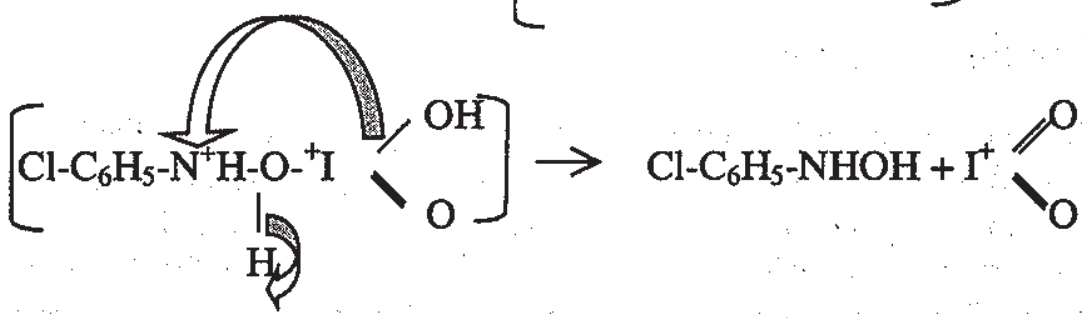




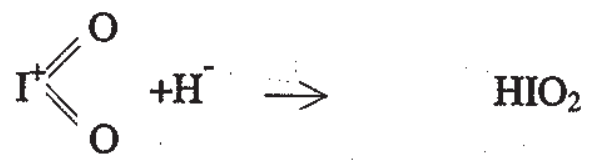

\section{Calculation of thermodynamic parameters}

1. By substituting the rate constant at the temperature of $312 \mathrm{~K}$ and $317 \mathrm{~K}$ we can calculate the energy of activation $=20.160 \mathrm{KJ} / \mathrm{mol}$.

2. Pre-exponential factor is substifuting energy of activation, the rate constant and temperature so the $A=3141.95 \mathrm{~S}^{-1}$

3. Enthalpy of activation is calculated by substituting the rate constant, temperature $\Delta \mathrm{H}^{\#}=17566.152 \mathrm{KJ} / \mathrm{mol}$

4. Substituting the rate constant, temperature, energy of activation we can calculate entropy of activation $\Delta S^{*}=-268.47 \mathrm{KJ} / \mathrm{mol}$

5. Free energy of activation is calculated by substituting the enthalpy of activation so we get $\Delta G^{*}=101.328 \mathrm{KJ} / \mathrm{mol}$.

\section{Conclusion}

Reaction follows First order kinetics with respect to oxidant and the complex with an energy of activation $20.160 \mathrm{KJ} / \mathrm{mol}$ and with the free energy of activation $101.328 \mathrm{KJ} /$ mol.

\section{References}

1. Devendran. N. Sharma and V.K.Guptha, Indian.J.chemistry, vol. I3A Jan (1975)

2. C.Srinivasan,P.Pandarakutty,N.arumugam, Indian. J.chemistry. vol.17A (1979).

3. Cotton. F.A and Wilkinson.G. (1980) Advanced Inorganic chemistry IV edition, New York Wiley inter science, Page 1340. 
4. Manikyamba, Raghunatha rao and sundaram, Indian. J. chemistry. vol.20A Dec (1981)

5. Vijayalakshmi,Manikyamba, sundaram J.Indian chemical soc., Vol.LX.July(1983)

6. Dedgaokar.c,.Mahajan. Indian .J.chemistry, vol.20A Dec (1981).

7. C.H.Sanjeeva reddy and E.V.Sundaram, Indian .J.chemistry. vol.23A Nov (1984).

8. P.S.Radhakrishnamoorthi and kiran .s.Tripathy, Indian J.chemistry. vol.25A Aug (1986).

9. Schwar Zunbach.G. (1960).Complexometric titrations, New York. 